\title{
The recovery of identity and relative position from visual input: Further evidence for the independence of processing of what and where
}

\author{
PHILIP T. QUINLAN \\ University of York, York, England
}

\begin{abstract}
Four experiments examined the manner in which item identity and relative position are recovered from visual input. A successive same/different matching paradigm was designed in which each trial contained a prime and a target display. Each display contained a reference object (i.e., a "+") and a located object (i.e., a letter, which fell to either the right or the left of the " + "). In Experiment 1 , subjects carried out identity judgments on the letters. Experiment 2 examined relative position judgments; in Experiment 3, subjects had to judge both item identity and relative position information. Overall, these initial data suggested that identity and positional information are recovered via independent mechanisms and that these operate concurrently. This suggestion was supported by the results of Experiment 4 , which in turn disconfirmed an alternative response account of performance.
\end{abstract}

This paper describes a set of experiments that were carried out in an attempt to further understand how item identity and item position are recovered from visual input. As with much recent research on the higher levels of vision, current interest in this particular topic can be traced to Treisman's early work on visual attention. In an important set of experiments, Treisman and Gelade (1980) examined subjects' ability to report the identity and location of a colored target letter in a briefly presented array of colored letters. Arrays contained two rows of six colored letters; only one of these was the target. Nontarget items were pink Os and blue Xs. In the feature condition, subjects had to report the location and identity of a target item that was an $\mathrm{H}$, an orange $\mathrm{X}$, or an orange $\mathrm{O}$. In the conjunction condition, the target item was either a pink X or a blue O. Performance in the conjunction condition showed that subjects performed no better than chance in reporting the identity of the target when they failed to correctly report the target's location. However, in the feature condition, the results appeared to show independence between the processing of identity and location. In the cases in which subjects incorrectly reported the location of the target, they were able to correctly report the target's identity on a statistically significant number of occasions. Within the standard feature integration account of performance, this pattern of results was taken to imply that preattentive processes could recover, at least, the identities of individual visual features in the absence of coding their locations. In contrast, the recovery of a partic-

Jeff Miller and Toby Mordkoff provided critical advice on how to generate the cumulative probability density functions. My thanks to both of them. Nick Hill also provided useful input in designing the final experiment. Correspondence should be addressed to P. Quinlan, Department of Psychology, University of York, Heslington, York YO1 5DD, England (e-mail: ptq1@york.ac.uk). ular conjunction of features depended on the contingent recovery of the location of that conjunction of features.

Controversy has surrounded this conclusion ever since the pattern of results was reported (see, e.g., Bundesen, 1991, 1993; Nissen, 1985; van der Velde \& van der Heijden, 1993). Indeed a quite different account of processing was put forward by Sagi and Julesz (1985) on the basis of performance in another type of visual search task. Here subjects were briefly presented with a mass of short diagonal lines. Embedded in this display were a small number of horizontal and vertical line targets. On each trial, this field of line segments was immediately masked by a new display containing randomly oriented arrowheads (i.e., Vs). In a detection task, subjects merely had to report the number of targets present. In a separate discrimination task, subjects had to report whether all the targets were of the same orientation or whether there was a single discrepant target. The duration of the target field was varied so that over trials the mean field duration to attain an accuracy level of $95 \%$ correct was plotted as a function of the number of targets in the displays. The results were clear-cut in showing that subjects' detection performance was unaffected by the number of targets present in the display; however, performance in the discrimination task suffered as the number of targets increased from two to three to four. Sagi and Julesz therefore arrived at a contradictory conclusion to that of Treisman and Gelade (1980) - who had argued that preattentive processes could recover the identities of individual visual features in the absence of coding their locations. According to Sagi and Julesz, performance in the detection task revealed that recovering the location of the targets occurred in parallel (i.e., it was due to the operation of preattentive processes), whereas identifying the targets relied on a serial process.

In attempting to replicate the results reported by Treisman and Gelade (1980), Johnston and Pashler (1990) 
carried out two experiments using variants on their feature search conditions in which subjects had to make an identity and a location response on every trial. One important aspect of the design was the inclusion of trials in which there was no target present. Inclusion of these trials allowed Johnston and Pashler to estimate any possible biases in guessing. Following careful and detailed analyses of the data, Johnston and Pashler concluded that "identity is only perceived if location is perceived, but location can sometimes be perceived without identity" (p. 854). The discrepancy between the results in the two studies was discussed, and given that the later study was much more tightly controlled than the earlier Treisman and Gelade study, the Johnston and Pashler conclusion about performance in these particular search conditions appears compelling. Such a conclusion is more in keeping with the ideas set out by Sagi and Julesz (1985) than with those set out by Treisman and Gelade.

Using a very similar task to that designed by Sagi and Julesz (1985), Atkinson and Braddick (1989) explored this topic in further detail. Here, displays were again briefly presented and followed by masked displays containing diagonal nontargets and a single horizontal or vertical target line segment. There were three separate conditions of interest. In the what task, subjects simply had to respond whether the target was horizontal or vertical. In the coarse where task, subjects had to respond as to whether the target was in the upper or lower half of the display. In the fine where task, subjects had to respond with which of four locations the target had occurred in. Again the duration of the target display was varied and the critical duration was where performance on a given task was at the $71 \%$ correct level. The data were clear in showing that the threshold duration was shortest in the coarse where task. Comparable and longer threshold durations were noted in the what and fine where tasks. This pattern of results was taken to suggest that a rather crude specification of a target's location can be recovered before the actual target's identity is available. However, a more detailed specification of position takes more time. Performance was not examined across a range of different target set sizes; hence no conclusions were drawn about possible qualitative differences in underlying processes.

All of the previously referenced research has been taken to show the degree to which the recovery of an item's location and its identity are dissociable. However, none of the studies have seriously addressed exactly how an item's location is actually encoded. More recently, though, interest has grown in how the visual system recovers a coding of relative position. For instance, Heathcote and Mewhort (1993) claim to have provided evidence for the parallel recovery of relative position information. They adapted the standard visual search paradigm by presenting subjects with arrays in which the to-be-searched elements were small rectangular boxes. Each box was made up of a pair of adjoining bars. In the monochrome condition, one of the bars was white and the other black. In the color condition, one of the bars was red and the other blue. In target-absent displays, the arrangement of the two bars was the same in all of the boxes (e.g., all blackwhite or all white-black). In target-present displays, all but one of the boxes had the same arrangement of the bars (i.e., the relative position of the bars was switched for the targets compared with the nontargets). The number of to-be-searched items was varied across trials and search performance was assessed for each display size. The data showed that, with practice (i.e., after approximately 1,600 trials), search performance was unaffected by display size - a standard feature pop-out effect was observed. Given this result, Heathcote and Mewhort concluded that relative position could be recovered preattentively. Indeed, similar patterns of performance were observed in the monochrome and color conditions; hence accounts based on direction of contrast could be ruled out in favor of accounts based on the parallel recovery of relative position. Against this, though, Wolfe (1994) has more recently argued that their data are perhaps best seen in terms of the operation of some form of early phasesensitive detecting mechanism, a possibility that points to the fact that their data provide no insights into how relative position is more generally recovered. Indeed, the preattentive processes they described are suggested by something called "learned pop-out" (p. 512). When subjects initially did the task, search times increased as a function of display size. However, after 1,600 trials, performance was unaffected by display size-hence the phrase "learned pop-out." A problem with this, though, is that the more typical finding is that featural pop-out is present from the earliest trials, and, more importantly, is unaffected in any critical way by practice (Treisman, Vieira, \& Hayes, 1992). It therefore seems more appropriate to argue that learned pop-out and featural pop-out are different and arise for different reasons (Treisman et al., 1992). On these grounds, whether or not relative position is recovered preattentively remains something of a contentious issue.

More recently, the recovery of relative position has also been examined by Logan and Compton (1996) using a different methodology to that of visual search. They developed variants of a statement verification task (after Clark \& Chase, 1972) in which subjects were asked to compare an initial written statement with a subsequently presented analogue (pictorial) display. Following the presentation of a central fixation cross, a statement in the form "B ABOVE D" was presented for $1 \mathrm{sec}$. At the offset of the statement, a picture display was presented until the subject made a response. The picture contained either two or nine letters; in both cases, the letters were printed in a single, central column. When nine letters were present, seven were nontargets. In addition to manipulating whether or not nontarget letters were presented along with target letters, Logan and Compton also varied the absolute distance between the target letters. The basic pattern of results was clear-cut. Response times (RTs) were unaffected when the distance between the target letters was varied and only the target letters were presented. However, 
RTs did increase as the number of intervening nontarget letters between the target letters increased. Interestingly, though, when the target and nontarget letters were presented in different colors, there was no longer a distance effect in the RT data. Logan and Compton discussed this particular pattern of results in terms of a multiprocess model of performance that also invoked a number of different putative representations. One such representation was described as the "spatial template" and was said to code regions of the visual input that contain "good, acceptable and bad examples of the predicated relation" (p. 160). Given that there was no effect of distance between the target letters on verification performance when no nontargets were presented, Logan and Compton invoked the notion of parallel processing as an explanatory construct. That is, they argued that comparisons between relevant objects in the input and those represented in the spatial template are carried out simultaneously for all points in the input.

This is not the place to provide a comprehensive summary of the theory described by Logan and Compton (1996), since the present study did not constitute a direct test of that theory. Rather, the primary aim was to attempt to further illuminate the manner in which identity and positional information are recovered from visual input. Some might wish to quibble with the distinction between relative and absolute position being mooted here on the grounds that all positions are coded relative to some frame of reference (Hinton, 1981). According to Hinton, there is no distinction between relative and absolute positional coding; everything is coded in relative terms. However, it is possible to distinguish the two by definition. Here the notion of absolute positional coding will be defined in terms of the most global and current frame of reference. Such a frame of reference has variously been termed an environmental, scene-based (Hinton \& Parsons, 1988; Quinlan, 1995), or exocentric (Howard, 1986) frame of reference. Simply put, with a scene-based coding system, the position of a given object is specified in terms of its spatial disposition relative to some form of scene-based frame of reference. According to Robertson (1995), a typical example of a scene-based frame, defined within an experimental setting, is that provided by the screen of a computer with the vertical midline of the screen being concordant with the gravitational vertical. Given this frame of reference, any display element that repeatedly appears in a particular screen position is said to occupy the same absolute position. The scene-based frame of reference therefore specifies the coordinates for locating all the objects in the current visual input.

Alternatively, it is also possible to think that the position of an object can be specified in terms of a more local frame of reference. For instance, Logan and Compton (1996) discussed the distinction between a reference $o b$ ject and a located object. By this account, the position of the located object is specified relative to that of the reference object. So in the statement "B ABOVE D," B is the located object and $\mathrm{D}$ is the reference object. $\mathrm{B}$ and $\mathrm{D}$ move around the screen but their relative positions remain constant; it is in this sense that absolute and relative positions can be dissociated (see Miller, 1988, for a similar discussion).

Although there is a sense in which the Logan and Compton (1996) study does address the issue of how both item identity and relative position are recovered from visual input, the particular paradigm they used does not seem to be an ideal tool for examining the issues in detail. For instance, the task entails translating a written statement into some form of representation that allows for comparisons with a nonlinguistic input. How such translation processes operate is not central to the debate about how item and location information are recovered. A more appropriate paradigm would thus be one in which the same sorts of inputs can be compared directly without the necessity of any additional translation processes. Moreover, the paradigm devised by Logan and Compton fails to provide data relevant to the issue of whether the processes that code identity and relative position operate independently or cooperatively. It is exactly this sort of issue that was central to the earlier work on the recovery of item identity and location.

In order to examine more directly how the visual system recovers item identity and relative position information, a variation on the same/different matching task was devised. In this task, subjects were presented with successive displays and were asked to respond either "same" or "different" on the basis of particular attributes in the displays. Each of the displays contained a letter positioned either to the right or the left of a cross. To use the terminology of Logan and Compton (1996), the cross is the reference object and the letter is the located object. The first display will be known as the "prime display" and the second display will be known as the "target display." On all trials, the prime display was located centrally with the cross occupying the center of the screen. After the offset of the prime display and following a short blank delay, the target display reappeared at the same screen position as the prime or in the periphery to the right or the left of the prime display. Subjects made same/different responses after the onset of the target display. Three experiments using this paradigm are reported, initially. In the first, an identity matching experiment, subjects had to judge the identities of the prime and target letters regardless of where on the screen they appeared. In the second, a relative position matching experiment, subjects had to judge the relative positions of the prime and target letters regardless of whether the letters were identical. Finally, in the identity and relative position matching experiment, subjects had to respond "same" only if the same letter appeared in the same relative position in the prime and target displays.

The rationale for these experiments was as follows. The results of Experiment 1 should reveal whether relative positional encoding influences the recovery of item identity. If the recovery of relative position operates according to the same principles as the recovery of absolute 
position, subjects should be facilitated in responding "same" when the prime and targets occupy the same relative positions as compared with when they occupy different relative positions. This is based on the assumptions that (1) relative position is recovered prior to item identity and (2) the analysis of relative position influences the identity judgment (see Lu \& Proctor, 1995, for a review of numerous studies showing effects of irrelevant location information on choice RTs). Experiment 2 tests a slightly different prediction and should reveal whether item identity influences the recovery of relative position. By a similar argument to that just advanced, two assumptions may be posited: (1) The analysis of relative position takes more time to complete than does the analysis of letter identity and (2) the latter influences the relative position judgment. Given these two assumptions, subjects should be facilitated in responding "same" when the letters are identical as compared with when they are not. To draw a crude analogy with Treisman's (1988) work, both Experiments 1 and 2 are, in a sense, feature tasks. Subjects had to judge the values of particular features in the displays. In contrast, Experiment 3 is a conjunction task because subjects had to judge a conjunction of features in the displays. Experiment 3 should thus reveal the manner in which the processes concerning the recovery of item identity and relative position proceed when values on both dimensions need to be integrated. Prior to the analysis of the data from Experiments 1 and 2 , there is little sense in trying to predict performance in this task.

Although the particular paradigm developed here is novel, its inspiration came in part from a study reported by Miller (1988). In Miller's study, subjects were given a pair of target letters to search for and, on each trial, a central fixation point was presented for $500 \mathrm{msec}$ and replaced immediately by a horizontal array of four to-besearched letters. On a random half of the trials, one of the two target letters was present in the display. In centered displays, the positions of the letters, relative to the fixation point (the " + "), were thus " $12+34$ "- -here a given digit signifies the position of a corresponding letter. In shift-right displays, the letter positions were thus " $1+234$," and in shift-left displays, the letter positions were thus " $123+4$." A given target letter was assigned a favored position defined relative to the locations used in the centered displays. Over the first two blocks of experimental trials, the target letter appeared in its favored position 22 times and 6 times in the other three positions. In the third block of experimental trials, both centered and shifted displays were presented. Part of the logic of the design was to try to separate out any position-specific effects from position-relative effects. Past work had shown that target detection is typically improved when the target is presented a likely location compared with when it appears at an unlikely location (e.g., Shaw \& Shaw, 1977). Miller decided to try to uncover the degree to which such a location probability effect is tied to absolute rather than relative positions. By way of further explanation, reconsider the notation introduced above to describe Miller's displays and assume that a favored target location in the centered displays is given by position 1. In a shift-left display, the same absolute position would be where the target appeared at position 2 , whereas the same relative position would be where the target appeared at position 1. Any facilitation in target detection could then be gauged in terms of absolute display coordinates (when the target appeared at position 2) and also in terms of relative display coordinates (when the target appeared at position 1).

Miller (1988) reported a strong absolute location probability effect in that subjects did detect targets better in the centered displays when a favored position was used than when a nonfavored position was used. In addition, an absolute location probability effect was found in shifted displays when the target fell at its favored position. Moreover, with shifted displays, subjects also benefited when the target occupied the same position relative to the favored position in the centered displays. Indeed, the sizes of the absolute and relative location probability effects were of the same magnitude when the data from the shifted displays were analyzed. Overall, therefore, the data provided good evidence that both absolute and relative position coding schemes are being tapped by the task.

In a second experiment, Miller (1988) tested the degree to which the absolute location probability effect was identity specific. To do this, he varied the probability of finding a particular target letter at a particular favored location. For a given favored position, one of the designated target letters (the inducing target) was more likely to be the occupant than the other (the test target). The test target was equally likely to fall at each of the four possible letter positions. As before, the data revealed a clear targetspecific location probability effect, with subjects responding rapidly when the inducing target fell at its favored location. However, subjects were also speeded in responding when the test target fell at the inducing target's favored location. In other words, subjects were facilitated in detecting either target when either target fell at the favored position. Overall, therefore, the data revealed both identity-specific and identity-independent location probability effects. Indeed, both sorts of location probability effects were found to exist for relative positions as well as for absolute positions when performance with shifted displays was tested. In order to account for both identityspecific and identity-independent location probability effects, Miller invoked a two-process model in which a moving spotlight of attention and position-specific letter detectors were assumed to operate. The moving spotlight was used to explain the identity-independent effectdirecting a spotlight to a particular location enhanced the processing of any target found at that position. In addition, position-specific letter detectors were used to explain the enhanced processing of a given target letter at a given (absolute) display position.

Testing Miller's (1988) particular two-process model of performance was not of primary concern; what was of interest was the theoretical implication that the recovery 
of relative position and identity may, in some sense, be due to independent processes. Indeed, the present experiments were intended to throw further light on the degree to which separate processing subsystems underlie the recovery of relative position and identity.

\section{GENERAL METHOD}

In all of the experiments the same equipment, layout of the equipment, timing parameters, and types of displays were used. To avoid unnecessary repetition, common features of the experiments will be conveyed first. Only detailed differences will be given in the description of the individual studies.

\section{Procedure}

The sequence of events on each trial was as follows. Initially a central fixation cross (i.e., a "+"; henceforth, CR1) was presented for $300 \mathrm{msec}$. Next, the prime letter was presented for $300 \mathrm{msec}$ to the right or the left of CR1. Both the cross and the prime letter remained on for $300 \mathrm{msec}$. Next, the screen went blank for $300 \mathrm{msec}$ and then the next fixation cross (henceforth, CR2) was presented for $300 \mathrm{msec}$. When this period had elapsed, the target letter was presented by the side of CR 2 until the computer detected a keypress. The intertrial interval (ITI) was set at approximately $1,600 \mathrm{msec}$. Whenever an error was detected, the computer sounded its bell and an additional $400 \mathrm{msec}$ was added to the ITI.

Each subject was tested individually in a small testing room. All the stimuli were presented on the screen of a 14" Acorn Color monitor interfaced to an Acorn Archimedes R260 computer. The monitor and computer were situated in adjoining rooms. Subjects faced the monitor and viewing distance was fixed at $50 \mathrm{~cm}$ by the positioning of a chinrest. Two response keys were also provided. Each of these was mounted on a small response box that was separately connected to the computer. Half the subjects responded "same" with their preferred hand.

Prior to testing, the nature of the task was explained to each subject, and each was given a block of practice trials. Subjects were informed that the computer's clock had started with the presentation of the target letter and that it had stopped with the detection of a keypress. Subjects were told to respond as quickly as possible without also committing too many errors. Further instructions were given during the first few practice trials. After the completion of the practice trials, subjects were asked to sign a consent form prior to the start of the experimental block of trials. The experimental trials were divided into four equally spaced blocks. Subjects initiated a block of trials by pressing a key on the computer's mouse.

\section{Design and Stimuli}

Only the capital letters $E$ and $F$ were used as the letter stimuli throughout, and a "+" was used as the reference object in both prime and target displays. The letters measured $0.46^{\circ} \times 0.57^{\circ}$ and the " + " measured $0.46^{\circ} \times 0.46^{\circ}$. When a letter was presented it was situated one character space (i.e., $0.46^{\circ}$ ) either to the right or the left of its corresponding reference cross. $E$ and $F$ were chosen because they are neither too easy nor too difficult to tell apart (Lindsay \& Norman, 1972, pp. 120-124). ${ }^{1}$

On one third of the trials, CR1 and CR2 occupied the same central location. For ease of exposition, these will be referred to as "central" trials. The remaining two thirds of trials were called "peripheral" trials. On one third of peripheral trials, CR2 appeared four character spaces to the left of CR1 (i.e., there were 3 spaces between $\mathrm{CR} 1$ and $\mathrm{CR} 2$ - a separation of $1.4^{\circ}$ ). These will be known as "left" trials. On the remaining third of the peripheral trials, CR2 appeared 4 character spaces to the right of CR1. These will be known as "right" trials. Overall, there were equal numbers of central, left, and right trials. Within these three sorts of trials, balancing was achieved by having equal numbers of same and different trials, by having an equal number of trials with $\mathrm{E}$ and $\mathrm{F}$ as the prime, and by having an equal number of trials in which the prime and target letters appeared on the same side of the reference cross and in which the target appeared on the other side to that of the prime.

In analyzing the data, a different description of the trials was adopted. Here central trials were the same as before, but it was possible to divide the peripheral trials up into ipsilateral and contralateral trials. Ipsilateral trials occurred when CR2 was presented on the same side as the prime letter. Contralateral trials occurred when CR2 was presented on the other side to that of the prime letter. The display characteristics were such that on ipsilateral trials, when the prime and target letters appeared on opposite sides of their respective reference crosses, they actually fell at the same screen position. In these cases, although the relative position of the two letters differed, their absolute position remained the same (after Miller, 1988). Figure 1 shows a schematic representation of the three sorts of same trials used in the experiments.

\section{EXPERIMENT 1 Identity Matching}

In this experiment, subjects were asked to make same/ different judgments on the basis of the identity of the letters. The positions of the prime and target letters were irrelevant to the task.

\section{Method}

Design. There was a basic set of 16 stimuli. (Here the term stimulus refers to a prime and target pair of displays presented on a given trial in the experiment.) These 16 were repeated three timesonce as central trials, once as left trials, and once as right trials- to give a total of 48 trials. These 48 trials were randomly ordered and were presented as the practice trials in the experiment. Ten multiples of these 48 trials were then presented as the experimental trials. Each set of 48 was randomized. The total 480 trials were divided into four blocks of 120 .

Subjects. Sixteen subjects selected from the Department of Psychology subject panel participated in the experiment. Student subjects received course credit for participation. There were 6 males and 10 females. All reported having normal or corrected-to-normal vision.

\section{Results and Discussion}

In all experiments, a standard approach to data analysis was adopted. Mean RTs were collected for each subject for each condition of interest. RTs of less than $100 \mathrm{msec}$ were treated as anticipations and were classified as outliers. In addition, all RTs $\pm 2.5 S D$ s away from a condition mean were also treated as outliers. Outliers were then classified as errors and were analyzed alongside the other incorrect responses. In the analyses reported, data for same and different trials were examined separately. Prior to the analysis of the error data, mean proportions were arcsine transformed, as advised by Winer (1962).

Performance on same trials. Summary statistics of the conditions of interest are shown in Table 1. The RT data for same trials were entered into a $3 \times 2$ repeated measures analysis of variance (ANOVA). Here display position (central, ipsilateral, contralateral) and letter position (same side, other side) were entered as fixed factors. Subjects was entered as a random factor. The analysis revealed a statis- 


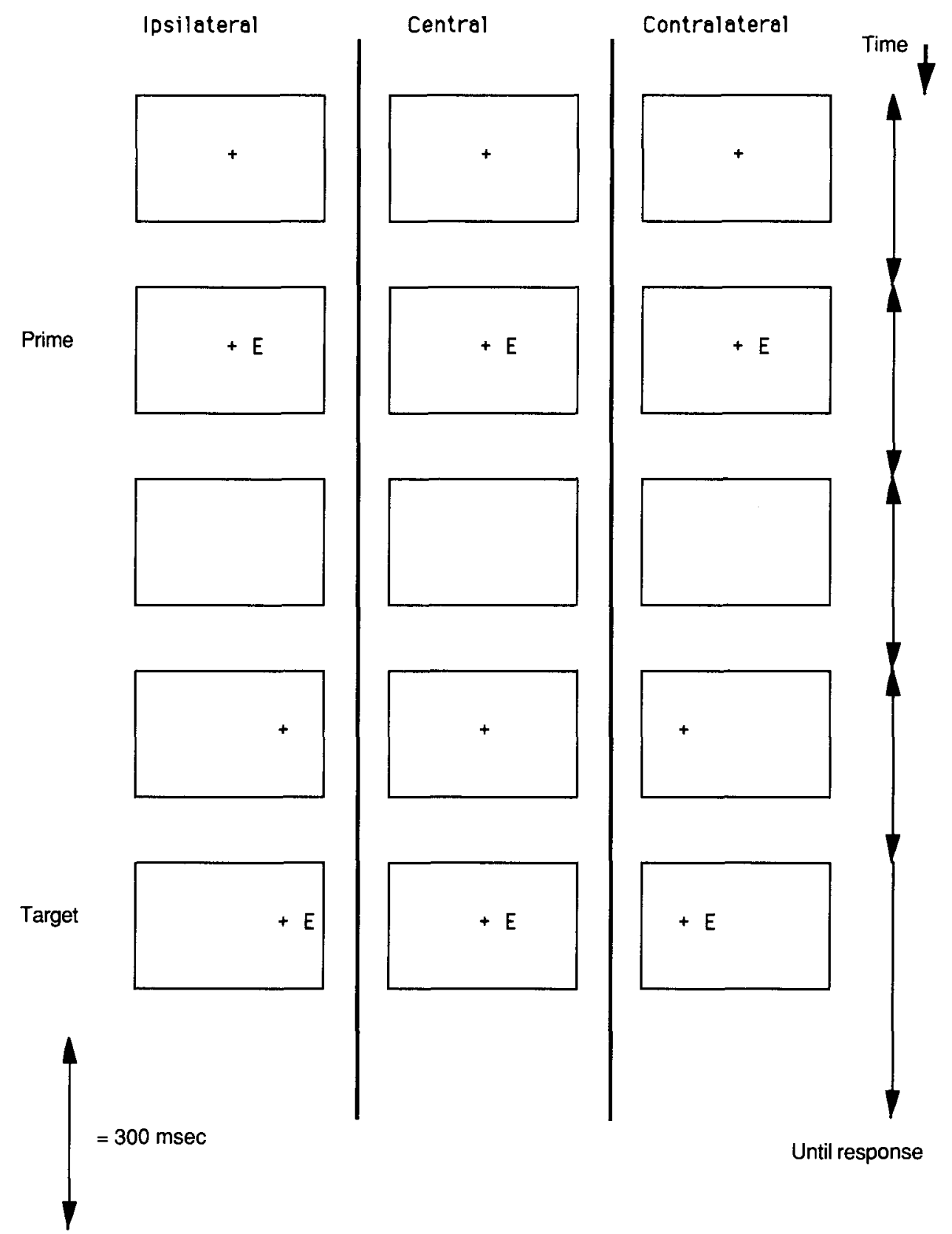

Figure 1. Schematic representation of the three sorts of same trials used in the experiments. (Drawing not to scale.)

tically significant main effect of letter position $[F(1,15)=$ $8.15, p<.05]$ and a statistically significant display position $\times$ letter position interaction $[F(2,30)=4.28, p<.05]$. The main effect of display position failed to reach statistical significance $[F(2,30)=1.45, p>.05]$.

Simple main effects analysis of the display position $x$ letter position interaction revealed that, whereas there was no effect of letter position for central and ipsilateral trials, there was a statistically significant effect of letter position for the contralateral trials $[F(1,15)=25.23, p<$ $.001]$. On contralateral trials, subjects were slower to respond "same" when the target letter appeared on the other side of the cross to that of the prime than when the target letter appeared on the same side of the cross to that of the prime. This shows that subjects were affected in making identity judgments only when the distance between the two letters was at its maximum - that is, when the target letter was at the furthest distance into the periphery. 
Table 1

Summary Statistics of Reaction Times (Means, in Milliseconds, With Standard Deviations) and Mean Percentage Error (PE) Data for Same Trials When Subjects Judged Letter Identity

\begin{tabular}{|c|c|c|c|c|c|c|c|c|c|}
\hline \multirow{3}{*}{$\begin{array}{c}\text { Letter } \\
\text { Position }\end{array}$} & \multicolumn{9}{|c|}{ Display Position } \\
\hline & \multicolumn{3}{|c|}{ Central } & \multicolumn{3}{|c|}{ Ipsilateral } & \multicolumn{3}{|c|}{ Contralateral } \\
\hline & $M$ & $S D$ & $\mathrm{PE}$ & $M$ & $S D$ & $\mathrm{PE}$ & $M$ & $S D$ & PE \\
\hline Same side & 498 & 76 & 7 & 512 & 76 & 7 & 495 & 68 & 7 \\
\hline Other side & 512 & 82 & 5 & 517 & 76 & 6 & 525 & 73 & 6 \\
\hline
\end{tabular}

Since there was only a $2 \%$ difference in mean error rates across the conditions of interest and since error rates were generally low (all less than $8 \%$ ), no statistical tests were carried out and it was concluded that error rates did not vary across the conditions. There was no evidence of any speed-error tradeoff.

Performance on different trials. Summary statistics of the conditions of interest are shown in Table 2. The RT data were analyzed in the same manner as described for same trials. There were no statistically significant effects in this data $[F<1.0$ for the display position main effect; $F(1,15)=2.17, p>.05$ for the letter position main effect; and $F(2,30)=1.78, p>.05$ for the display position $\times$ letter position interaction].

As with the data from same trials, there was only a $2 \%$ difference in mean error rates across the conditions of interest and error rates were generally low (all less than $9 \%$ ). Therefore, no statistical tests were carried out and it was concluded that error rates did not vary across the conditions. There was no evidence of any speed-error tradeoff.

The present data have revealed a robust and general pattern; generally speaking, subjects were unaffected by the relative positions of the prime and the target letters when asked to judge the identity of the two letters. Nevertheless, subjects were slower to secure a match when the absolute distance between the prime and the target letters was the largest used-that is, when the target letter was moved furthest into the periphery. This particular effect might well reflect the decrease in visual acuity with increases in retinal eccentricity (Anstis, 1974); however, it is not of central import here. No other effects were statistically significant in the experiment. The results of this experiment have shown that subjects were able to make judgments about letter identity regardless of whether the letter's relative position changed across the prime and target displays or stayed the same. In other words, the data are consistent with the notion that the coding of item identity and the coding of location are independent. Moreover, the data might be taken to support the view that the recovery of relative position occurs after the recovery of item identity.

\section{EXPERIMENT 2 Relative Position Matching}

In this experiment, subjects made "same" responses when the prime and the target letter appeared in the same position relative to their own reference cross-that is, when both the prime and the target letters were on either the right or the left of the cross. The identities of the prime and the target were irrelevant to the task. The breakdown of trials in the experimental session was the same as in Experiment 1.

\section{Method}

Subjects. Twelve subjects selected from the Department of Psychology subject panel participated in the experiment. Student subjects received course credit for participation. There were 10 females and 2 males. All reported having normal or corrected-to-normal vision.

\section{Results and Discussion}

Performance on same trials. Summary statistics of the conditions of interest are shown in Table 3. The RT data for same trials were entered into a $3 \times 2$ repeated measures ANOVA. Here display position (central, ipsilateral, contralateral) and letter identity (same, different) were entered as fixed factors. Subjects was entered as a random factor. The analysis revealed statistically significant main effects of display position $[F(2,22)=26.05$, $p<.001]$ and letter identity $[F(1,11)=12.81, p<.01]$. The display position $\times$ letter identity interaction failed to reach statistical significance $(F<1.0)$. The overall pattern of results revealed that subjects were faster to respond "same" when the displays were presented centrally than peripherally. In addition, subjects were faster to respond "same" when the prime and the target were identical than when they were different.

The transformed error data were entered into the same sort of ANOVA as that used with the RT data. This analysis revealed that only the main effect of display position reached statistical significance $[F(2,22)=7.13, p<.01$; $F<1.0$ for both the main effect of letter identity and the display position $\times$ letter identity interaction]. Overall, therefore, subjects were less accurate when the targets were presented peripherally than when they were presented centrally. This is consistent with the absence of any speed-error tradeoffs.

Performance on different trials. Summary statistics of the conditions of interest are shown in Table 4. The RT data were analyzed in the same manner as described for same trials. This analysis revealed that only the main effect of display position reached statistical significance $[F(2,22)=$ $4.55, p<.05 ; F<1.0$ for the letter identity main effect and the display position $\times$ letter identity interaction].

The transformed error data were entered into the same sort of ANOVA as that used with the RT data. Neither

\section{Table 2}

Summary Statistics of Reaction Times (Means, in Milliseconds, With Standard Deviations) and Mean Percentage Error (PE) Data for Different Trials When Subjects Judged Letter Identity

\begin{tabular}{|c|c|c|c|c|c|c|c|c|c|}
\hline \multirow{3}{*}{$\begin{array}{l}\text { Letter } \\
\text { Position }\end{array}$} & \multicolumn{9}{|c|}{ Display Position } \\
\hline & \multicolumn{3}{|c|}{ Central } & \multicolumn{3}{|c|}{ Ipsilateral } & \multicolumn{3}{|c|}{ Contralateral } \\
\hline & $M$ & $S D$ & $\mathrm{PE}$ & $M$ & $S D$ & $\mathrm{PE}$ & $M$ & $S D$ & $P$ \\
\hline & 546 & 7 & 8 & 5 & 68 & & , & 68 & \\
\hline Other side & 536 & 70 & 6 & 538 & 75 & 6 & 540 & 68 & \\
\hline
\end{tabular}


Table 3

Summary Statistics of Reaction Times (Means, in Milliseconds, With Standard Deviations) and Mean Percentage Error (PE) Data for Same Trials When Subjects Judged Relative Position

\begin{tabular}{|c|c|c|c|c|c|c|c|c|c|}
\hline \multirow{3}{*}{$\begin{array}{c}\text { Letter } \\
\text { Identity }\end{array}$} & \multicolumn{9}{|c|}{ Display Position } \\
\hline & \multicolumn{3}{|c|}{ Central } & \multicolumn{3}{|c|}{ Ipsilateral } & \multicolumn{3}{|c|}{ Contralateral } \\
\hline & $M$ & $S D$ & $\mathrm{PE}$ & $M$ & $S D$ & $\mathrm{PE}$ & $M$ & $S D$ & $\mathrm{PE}$ \\
\hline Same & 507 & 112 & 7 & 551 & 104 & 10 & 563 & 132 & 11 \\
\hline Different & 534 & 138 & 7 & 584 & 122 & 12 & 584 & 136 & 10 \\
\hline
\end{tabular}

the main effect nor the interaction reached statistical significance $[F(2,22)=2.10, p>.05$ for the display position main effect; $F<1.0$ for the letter identity main effect, and the display position $\times$ letter identity]. This is consistent with the absence of any speed-error tradeoff.

As with the data in Experiment 1, the pattern of results found here is relatively clear-cut. When subjects judged the relative positions of the prime and target letters, there were reliable effects of both overall display position and letter identity. Subjects were faster to make relative position judgments when the target display was presented centrally than when it appeared peripherally. This pattern obtained on both same and different responses. Moreover, subjects were slower in responding "same" when the prime and target letters were different than when they were identical (even though letter identity was irrelevant to the task). Evidently, subjects were influenced by the identity of the letters when making relative position judgments about them.

One account for the overall pattern of performance across Experiments 1 and 2 would be that item identity and relative position are derived from separate processes and that the recovery of item identity occurs prior to the recovery of relative position. At a rather general level, this kind of account appears to contrast with that developed in the earlier literature on the recovery of absolute position and identity - namely that location information is available prior to identity. Indeed, the results do appear to stand in contrast to the location dominance hypothesis put forward by Tsal and Lavie (1993; see also Cave \& Pashler, 1995). According to this hypothesis, attending "to any aspect of the stimulus entails directing attention to its location" (p. 137). By this hypothesis, it would have been reasonable to predict that position change would affect responding to identity of the target letter and not that a change in identity would affect responding to relative position. Upon reflection, though, the present data do not necessarily contradict the location dominance hypothesis. Regardless of whether or not attention was directed to the actual location of the target letter, this does not necessarily entail recovering a representation of its position relative to the reference cross in the displays. Subjects may have recovered the target's absolute position (as defined in terms of the screen's coordinates) in making the identity judgment, but may not have coded its position as defined relative to the cross. There was no requirement in Experiment 1 to compute the target's po- sition relative to the reference cross in order to do the task (cf. Logan, 1995). Further discussion of these possibilities is postponed until after the discussion of Experiment 3.

\section{EXPERIMENT 3 Judging Both Identity and Relative Position}

In this experiment, subjects made "same" responses when the same letter appeared on the same side of the cross in the two letter displays.

\section{Method}

Design. There was a basic set of 24 stimuli. These 24 stimuli were repeated three times - once as central trials, once as left trials, and once as right trials-for a total of 72 trials. These 72 trials were randomly ordered, the first 30 were presented as practice trials. Ten multiples of these 72 trials were then presented as the experimental trials. Each set of 72 was randomized individually. The total 720 trials were divided into four blocks of 180 .

Subjects. An initial set of 12 subjects selected from the Department of Psychology subject panel participated in the experiment. However, due to excessively slow RTs, 1 subject was replaced to give a final set of 12 acceptable subjects. There were 3 males and 9 females. All reported having normal or corrected-to-normal vision.

\section{Results and Discussion}

Performance on same trials. Summary statistics of the conditions of interest are shown in Table 5. The RT data for same trials were entered into a one-way repeated measures ANOVA. Here the fixed factor of interest was display position (central, ipsilateral, and contralateral). Subjects was entered as a random factor. The analysis revealed a statistically significant main effect of display position $[F(2,22)=9.10, p<.001]$. An HSD test revealed that subjects were overall fastest in responding when the prime and target letters fell at the same central screen location $(p<.05$ for the comparison with the contralateral data, and $p<.01$ for the comparison with the ipsilateral data). Overall, subjects were slower in responding "same" when the target letter appeared in the periphery than when it appeared centrally.

As there was only a $1 \%$ difference in error rates across the three conditions, no statistical tests were carried out, and it was concluded that error rates did not vary across the conditions. There was no speed-error tradeoff.

Performance on different trials. Initially, the data on different trials were entered into a single analysis in which the performance on central and peripheral display trials could be compared in a manner similar to that used with

Table 4

Summary Statistics of Reaction Times (Means, in Milliseconds, With Standard Deviations) and Mean Percentage Error (PE) Data for Different Trials When Subjects Judged Relative Position

\begin{tabular}{|c|c|c|c|c|c|c|c|c|c|}
\hline \multirow{3}{*}{$\begin{array}{c}\text { Letter } \\
\text { Identity }\end{array}$} & \multicolumn{9}{|c|}{ Display Position } \\
\hline & \multicolumn{3}{|c|}{ Central } & \multicolumn{3}{|c|}{ Ipsilateral } & \multicolumn{3}{|c|}{ Contralateral } \\
\hline & $M$ & $S D$ & $\mathrm{PE}$ & $M$ & $S D$ & PE & $M$ & $S D$ & $\mathrm{PE}$ \\
\hline & 92 & 125 & 7 & 621 & 147 & 10 & 6 & 12 & 8 \\
\hline ifferent & 584 & 123 & 7 & 617 & 164 & 10 & 617 & 138 & 7 \\
\hline
\end{tabular}


Table 5

Summary Statistics of Reaction Times (Means, in Milliseconds, With Standard Deviations) and Mean Percentage Error (PE) Data for Same Trials When Subjects Judged Both Letter Identity and Relative Position

\begin{tabular}{lccc}
\hline & \multicolumn{3}{c}{ Same Trials } \\
\cline { 2 - 4 } Condition & $M$ & $S D$ & PE \\
\hline Central & 474 & 134 & 6 \\
Ipsilateral & 517 & 140 & 7 \\
Contralateral & 499 & 145 & 7 \\
\hline
\end{tabular}

the data for same trials. Summary statistics of the conditions of interest are shown in Table 6 . The RT data for different trials were entered into a $2 \times 3$ repeated measures ANOVA. Display position (central and peripheral) and identity/side (same identity/other side, different identity/same side, and different identity/other side) were entered as fixed factors. Subjects was entered as a random factor. The analysis revealed statistically significant main effects of display position $[F(1,11)=9.99, p<.01]$ and identity/side $[F(2,22)=11.72, p<.001]$. The display position $X$ identity/side interaction failed to reach statistical significance $(F<1.0)$.

The statistically significant main effect of display position revealed that subjects were quicker in responding "different" when the target letter was presented centrally than when it was presented peripherally. In order to examine the statistically significant main effect of identity/ side further, an HSD test was carried out. This revealed that subjects were fastest in responding to the different identity/other side displays ( $p<.01$, both comparisons). There was no difference in RTs to the same identity/other side and the different identity/same side displays $(p>.05)$.

The transformed errors were analyzed in the same manner as the RTs. This analysis revealed the same pattern of results. The main effects of both display position $[F(1,11)=7.85, p<.05]$ and identity/side $[F(2,22)=$ $4.08, p<.05]$ were statistically significant. The display position $\times$ identity/side interaction failed to reach statistical significance $(F<1.0)$. The main effect of display position revealed that subjects were more accurate in responding "different" when target letter was presented centrally than when it was presented peripherally. An HSD test of the main effect of identity/side revealed that subjects made more errors to the different identity/same side displays than to the different identity/other side displays $(p<.05)$. No other comparisons reached statistical significance $(p>.05)$. Generally, the pattern of results was the same for the RTs and the error data. There were no signs of any speed-error tradeoffs.

To further analyze performance with the peripheral displays, a more detailed breakdown of the data was carried out. Table 7 shows summary statistics of the conditions of interest. The RT data were entered into a $3 \times 2$ repeated measures ANOVA in which display type (same identity/other side, different identity/same side, and different identity/other side) and display position (ipsilateral and contralateral) were entered as fixed factors and subjects was entered as a random factor. This analysis revealed a statistically significant main effect of display type $[F(2,22)=14.79, p<.001]$. Neither the main effect of display position $(F<1.0)$ nor the display type $\times$ display position interaction $[F(2,22)=1.41, p>.05]$ reached statistical significance. An HSD test of the main effect of display type revealed that subjects were overall quickest in responding to the different identity/other side displays $(p<.01$ for the comparisons with performance on the same identity/other side trials and the different identity/same side trials; performance on the latter two trial types did not differ, $p>.05$ ).

An analogous analysis of the transformed error data revealed again that only the main effect of display type reached statistical significance $[F(2,22)=6.34, p<.01$; $F<1.0$ for the main effect of display position, and $F(2,22)=1.90, p>.05$ for the display type $\times$ display position interaction]. An HSD test of the main effect of display type revealed that subjects were overall most accurate in responding "different" to the different identity/ other side displays ( $p<.01$ for the comparisons with performance on the same identity/other side trials and the different identity/same side trials; performance on the latter two trial types did not differ, $p>.05$ ).

To summarize the argument so far: The data from both Experiments 1 and 2 have been taken to suggest that the processing of item identity and relative position information is carried out by different subsystems. The data are also consistent with the view that item identity is recovered prior to relative position. Whereas subjects were unaffected by changes in relative position when responding on the basis of item identity, changes in item identity did exert an effect on responding to relative position. This pattern of results is consistent with a strictly serial account of processing; namely, identity is computed first and then relative position is recovered. In contrast to this, though, the data from Experiment 3 show an effect that might otherwise be interpreted in terms of some form of concurrent processing of identity and relative position. The most robust finding in the data for the different trials is that subjects responded most quickly when the prime and target letters were different letters and appeared on different sides of the crosses in the prime and target

Table 6

Summary Statistics of Reaction Times (Means, in Milliseconds, With Standard Deviations) and Mean Percentage Error (PE) Data for Different Trials in the Analysis Comparing Performance With Central and Peripheral Displays When Subjects Judged Both Letter Identity and Relative Position

\begin{tabular}{|c|c|c|c|c|c|c|}
\hline \multirow{3}{*}{$\begin{array}{l}\text { Experimental } \\
\text { Task }\end{array}$} & \multicolumn{6}{|c|}{ Different Trials } \\
\hline & \multicolumn{3}{|c|}{ Central } & \multicolumn{3}{|c|}{ Peripheral } \\
\hline & $M$ & $S D$ & $\mathrm{PE}$ & $M$ & $S D$ & $\mathrm{PE}$ \\
\hline $\begin{array}{l}\text { Same identity/ } \\
\text { other side }\end{array}$ & 572 & 120 & 7 & 590 & 123 & 9 \\
\hline $\begin{array}{l}\text { Different identity/ } \\
\text { same side }\end{array}$ & 570 & 90 & 8 & 603 & 97 & 10 \\
\hline $\begin{array}{l}\text { Different identity/ } \\
\text { other side }\end{array}$ & 532 & 103 & 4 & 547 & 107 & \\
\hline
\end{tabular}


Table 7

Summary Statistics of Reaction Times (Means, in Milliseconds, With Standard Deviations) and Mean Percentage Error (PE) Data for Different Trials in the Analysis of the Peripheral Displays Alone When Subjects Judged Both Identity and Relative Position

\begin{tabular}{|c|c|c|c|c|c|c|}
\hline \multirow{3}{*}{$\begin{array}{l}\text { Experimental } \\
\text { Task }\end{array}$} & \multicolumn{6}{|c|}{ Different Trials } \\
\hline & \multicolumn{3}{|c|}{ Ipsilateral Displays } & \multicolumn{3}{|c|}{ Contralateral Displays } \\
\hline & $M$ & $S D$ & $\mathrm{PE}$ & $M$ & $S D$ & $\mathrm{PE}$ \\
\hline $\begin{array}{l}\text { Same identity/ } \\
\text { other side }\end{array}$ & 561 & 122 & 10 & 582 & 110 & 8 \\
\hline $\begin{array}{l}\text { Different identity/ } \\
\text { same side }\end{array}$ & 597 & 79 & 11 & 591 & 111 & 8 \\
\hline $\begin{array}{l}\text { Different identity/ } \\
\text { other side }\end{array}$ & 539 & 116 & 4 & 532 & 104 & 6 \\
\hline
\end{tabular}

displays. One way of thinking about this result is in terms of redundancy gain (Egeth \& Mordkoff, 1991). Subjects were facilitated in responding "different" when both the identity and the relative position differed across the prime and target displays. This was the case even though the detection of either an identity or a relative position mismatch would have been sufficient for a response to be executed. Typically, redundancy gains have been discussed in the context of redundant information supporting a positive response (see, e.g., Mordkoff \& Yantis, 1991). Such an effect has been shown repeatedly in tasks in which either a single letter or a pair of letters is present on each trial and subjects make one response when they identify one particular letter and a different response when they detect another. The interesting point is that subjects respond more quickly when a pair of letters is presented and both letters are identical than when only a single letter is presented (see, e.g., Mordkoff \& Yantis, 1991, for discussion). Such a redundancy gain effect has also been termed a redundant signals effect on the grounds that detection of either target letter alone is sufficient to make a response. In the present context, the intention was to examine a redundancy gain effect in which the actual effect was shown as facilitation in making a negative response. Subjects were facilitated in responding "different" when mismatches arose on two separate dimensions compared with when only a single mismatch occurred. This redundancy gain effect suggested that a further exploration of the data might throw more light on how identity and relative position were recovered from the displays.

As a simplifying step, only the data from the central different trials were analyzed further. These were broken down into same identity/other side, different identity/same side, and different identity/other side categories. (The data from the peripheral trials showed the same pattern as these data.) All of the raw data for these three types of trials were considered and prior to further analysis the "kill-the-twin" procedure was enacted (Eriksen, 1988). In this procedure, each set of data was considered in turn, and the RTs for correct responses and errors were separately rank-ordered. Next, the nearest correct RT to each error RT was removed. This procedure provides a reason- ably principled means for removing fast-guess responses from the correct RT distribution (Mordkoff, Yantis, \& Egeth, 1990). Then, separate Vincentized cumulative density functions (Ratcliff, 1979) were derived for the three categories of trials. These are shown in Figure 2.

This figure illustrates that subjects were quicker in responding "different" on the different identity/other side condition than in the same identity/other side and the different identity/same side conditions across the complete range of RTs. In other words, the redundancy gain effect is evident across the entire range of RTs. A more detailed approach to the analysis of these data is possible through adapting the methods outlined initially by Miller (1982).

A basic assumption of this approach is that it is possible to describe an "identity" processing channel and a "relative position" processing channel. The aim now was to try to ascertain whether these are entirely separate in their operation or whether there is a sense in which they interact. In pursuing this characterization, it is possible to describe a separate activation model and a coactivation model. According to the separate activation model, independent signals on the two channels produce separate activations, each of which can produce a response. Such ideas underlie the familiar "horse race models" of processing (Miller, 1982). By such a view, and in terms of the present task, as soon as the target display is presented an identity signal is propagated down the identity channel, and concurrent with this, a relative position signal is propagated down the relative position channel. Given this, subjects should be able to make a different response as



Figure 2. Graph showing the cumulative probability density functions for the same identity/other side trials, the different identity/same side trials, and the different identity/other side trials. 
soon as they detect either a difference in identity or relative position across the two displays. In contrast, when only one channel delivers a mismatch, performance is determined by the time to complete on this particular channel. Alternatively, the coactivation model assumes that the separate signals are in some sense pooled prior to response execution. As a consequence faster responses can be made in the presence of two mismatches than in the presence of a single mismatch because of an increase in levels of arousal and/or activation of recognition responses (Eriksen, Goettl, St. James, \& Fournier, 1989). Both sorts of models assume the concurrent processing of identity and relative position: The critical difference is that whereas the separate activation model assumes the complete independence of processing of identity and relative position, the coactivation account posits interdependence of processing.

It is possible to characterize the predicted behavior of these models more formally. Here a basic assumption is that each signal on the separate channels (i.e., $\mathrm{C}_{1}$, the identity channel, and $\mathrm{C}_{2}$, the relative position channel) may be modeled by the distribution of a random variable. When redundant information is provided on a trial (as is the case on different identity/other side trials), the response latency must conform to the following expression:

$$
\begin{array}{r}
P\left[\mathrm{RT}\left(t \mid \mathrm{C}_{1} \text { and } \mathrm{C}_{2}\right]=P\left(\mathrm{RT}<t \mid \mathrm{C}_{1}\right)+P\left(\mathrm{RT}<t \mid \mathrm{C}_{2}\right)\right. \\
-P\left(\mathrm{RT}<t \mid \mathrm{C}_{1}\right) \text { and }\left(\mathrm{RT}<t \mid \mathrm{C}_{2}\right) .
\end{array}
$$

$P\left[\mathrm{RT}\left(t \mid \mathrm{C}_{1}\right.\right.$ and $\left.\left.\mathrm{C}_{2}\right)\right]$ stands for the cumulative probability density function (CDF) of RT on redundant trials. $P(\mathrm{RT}<$ $\left.t \mid \mathrm{C}_{1}\right)$ and $P\left(\mathrm{RT}<t \mid \mathrm{C}_{2}\right)$ stand for the CDFs for the cases in which information on only one channel is available (as is the case on the same identity/other side trials and the different identity/same side trials). According to Miller (1982), the final term in the equation reflects the correlation between the signals on the two channels and is not directly observable. Discounting this final term, Miller (1982) argued that a general prediction of all separate activation models is as follows:

$$
\begin{aligned}
& P\left[\mathrm{RT}\left(t \mid \mathrm{C}_{1} \text { and } \mathrm{C}_{2}\right)\right] \leq P\left(\mathrm{RT}<t \mid \mathrm{C}_{1}\right) \\
& \qquad+P\left(\mathrm{RT}<t \mid \mathrm{C}_{2}\right) .
\end{aligned}
$$

This means that the probability of making a response on a redundant trial by a particular time, $t$, cannot exceed the sum of probabilities of making a response by the same time on a single signal trial. This holds for each response latency across the entire range of response latencies.

To examine this postulate in the present case, the following steps were taken. First the CDF for the redundant signals trials was examined. This had already been computed and is shown in Figure 2. The critical points on this curve are plotted as quantiles starting at the 5\% level. Each RT for each of these points was noted. Percentile points were now computed for each of the separate signal distributions for every millisecond across the entire range. The sum of these distributions was computed by adding together the percentage of RTs made for each millisecond. Critical points now were where the sum of the percentages first exceeded the corresponding quantile computed for the redundant signals CDF. The RTs at these points were noted and were used to define the summed CDF for the two separate signals. Figure 3 shows the CDF for the redundant signals trials as before, together with the summed CDF.

Visual inspection of this figure reveals very little evidence of violations of the inequality expressed in Equation 2. Indeed it is only for the shortest RTs at the 5\% level that the redundant signals CDF is to the left of the summed CDF; such a case typically signifies a violation of the inequality. However, a statistical comparison of this case revealed that there was no difference between two points on these two curves $[t(11)=0.45, p>.05$, two-tailed test]. Given this result, it is possible to conclude that the present data are entirely consistent with a separate activation-and not a coactivation-model of the processing of identity and relative position.

This result shows that when subjects had to integrate both item identity and relative position information, the recovery of these different characteristics proceeded independently. The particular model tested also assumed that both characteristics were processed concurrently without cooperation. This particular conclusion appears to contrast with the results of Experiments 1 and 2, in which a preliminary conclusion was that the recovery of identity preceded that of relative position. However, the task demands of Experiment 3 were quite different from those in the previous experiments. In Experiment 3, sub-

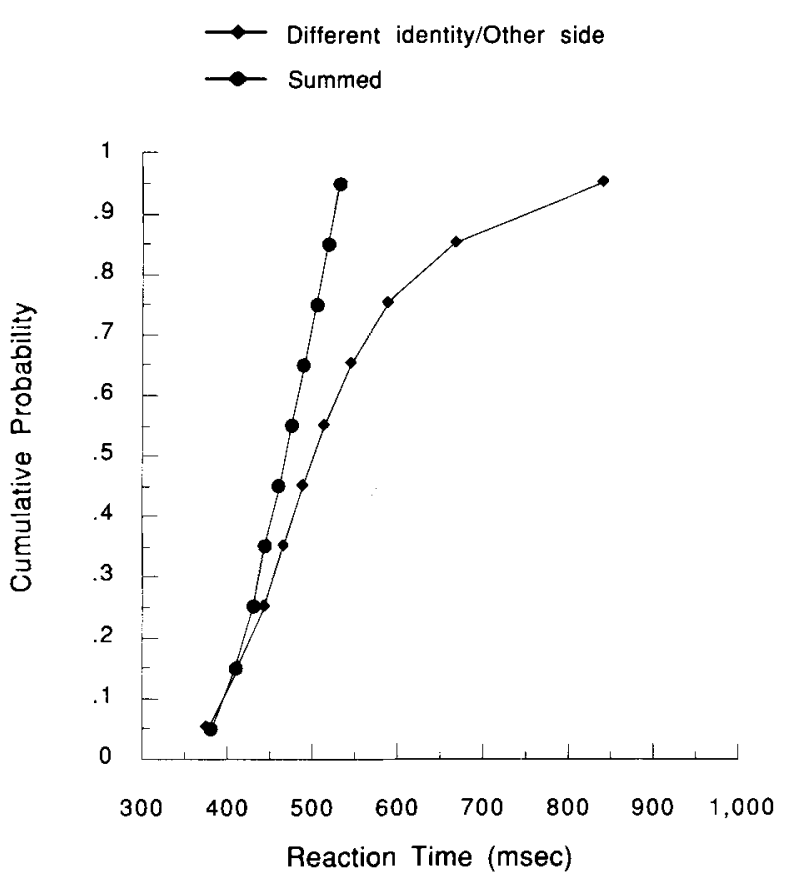

Figure 3. Graph showing the cumulative probability density function for the different identity/other side trials and the summed cumulative probability density function for the same identity/ other side and the different identity/same side trials. 
jects had to coordinate both identity and relative position information to respond correctly. On the assumption that identity information is available prior to relative position, it might have been predicted that subjects should have been able to respond "different" as soon as a mismatch occurred on the identity dimension-that is, when the prime and target letters differed. However, subjects did not use such a strategy because just attending to the dimension would not have been sufficient to the task. On some trials, although the prime and target letters were identical, their relative positions differed across the prime and target displays. On these trials, a different response was required. The data show that subjects had to, in a sense, wait until information about identity and relative position had been integrated before they were able to respond.

Before a more detailed account of performance is discussed, it seems important to consider and, perhaps rule out, a more mundane explanation. ${ }^{2}$ By this account, performance in the tasks may reflect nothing more than the operation of response mechanisms; consequently, it would be a mistake to attempt to argue that the results reveal anything of interest about perceptual mechanisms (see Farell, 1985, for a more thorough discussion of similar "response priming" accounts of performance). Simply put, the pattern of performance on different trials in Experiment 3 may reflect a congruence effect operating at the response stage of processing. By this account, subjects were slowed in responding "different" on the same identity/other side and the different identity/same side trials because in each case, information on one of the dimensions (either identity or relative position, respectively) produced a match or same signal. In contrast, on the different identity/other side trials, information on both dimensions resulted in mismatches; both dimensions produced a different signal. According to the congruence account, therefore, the redundancy gain effect should be interpreted as showing that subjects were slowed in responding on the same identity/other side and the different identity/same side trials rather than being speeded in responding on the different identity/other side trials. Such a congruence account is plausible since the task demanded that subjects monitor information from both dimensions throughout the course of the experiment. As a direct test of this account, a final experiment was designed in which distinct types of different trials occurred in separate blocks.

\section{EXPERIMENT 4 \\ Testing the Congruence Account of Performance}

In a bid to address the congruence account of performance, the final experiment tested subjects on, essentially, three distinct experimental tasks. In all three tasks, the stimulus presentation, equipment, and procedure were identical to those described before; subjects made same/different responses to successive displays containing a cross and a letter. Moreover, in each of the tasks, subjects were instructed to respond "same" if the same letter appeared on the same side of the cross in the two displays. However, the nature of the different trials varied across the three tasks. On every different trial in the different side task, the identity of the letter was maintained across the two displays, but its relative position changed. In the different identity task on every different trial, a different letter appeared across the two displays, but the relative position of the letter remained unchanged. Finally, in the both different task on different trials, both the identity and relative position of the letter changed across the two displays. Subjects were fully informed about the nature of the different trials prior to performing the individual tasks. On these grounds, it seemed plausible to assume that subjects would attend primarily to relative position in performing the different side task and that they would attend primarily to identity in performing the different identity task. In both of these single-dimension tasks, information on the noncritical dimension was irrelevant to the correct response. In contrast, in the both different task, a correct response could be made on the basis of information on either dimension.

The primary aim of this experiment was to further examine performance on different trials. According to the congruence account of performance, the redundancy gain effect arose in Experiment 3 because subjects were slowed in responding "different" when a match arose on either of the identity or relative position dimensions: The redundancy gain arose not so much because of the "gain" in response speed on the different identity/other side trials, but because of a retardation in response speed on same identity/other side and different identity/same side trials. Consistent with this is the fact that, by necessity, subjects had to monitor both dimensions throughout the experiment in order to comply with the task demands. In monitoring both dimensions, subjects may well have registered both the match and mismatch on the same identity/ other side and the different identity/same side trials. In a bid to circumvent this, in the next experiment, subjects only needed to attend to a single dimension in order to respond appropriately. For example, in the single-dimension tasks, subjects only needed to monitor information on the relevant dimension. In addition, subjects could respond appropriately in the both different task by also monitoring a single dimension. Moreover, on the assumption that information on one of the dimensions is resolved faster than the other, and that subjects base their responses on the information on this dimension, the speed of responding "different" in the both different task ought to be no faster than responding "different" in the "fastest" singledimension task. For example, given that identity is resolved faster than relative position, and that subjects base their responses on identity information, they would be as quick to detect a difference when the identities mismatched in the different identity task as they would be in the both different task. In contrast, if the previous redundancy gain effect is truly a reflection of perceptual mechanisms, the prediction is that it will obtain in the present experiment. 


\section{Method}

Design. The experiment comprised the three tasks described previously. Each of these tasks mapped onto a block of practice trials and three blocks of experimental trials. In each task, there were 30 practice trials followed by three blocks of 72 experimental trials. For each task, there was a basic set of eight stimuli-four same stimuli and four different stimuli. Three multiples of these eight stimuli gave a basic set of 24 stimuli. This set of 24 stimuli was repeated three times-once as central trials, once as left trials, and once as right trials - to give a total of 72 trials. These 72 trials were randomly ordered, the first 30 were presented as practice trials. Three multiples of these 72 trials were then presented as the experimental trials. Each multiple of 72 was randomized individually. The total 216 trials were divided into three blocks of 72 .

The order of the three tasks was balanced so that a different sequence was administered to each of a set of 6 subjects. Two sets of subjects were tested in the experiment. For one set, same responses were made with the preferred hand, and for the other set of subjects, different responses were made with the preferred hand.

Subjects. Twelve subjects selected from the Department of Psychology subject panel participated in the experiment. There were 6 males and 6 females. All reported having normal or corrected-tonormal vision.

\section{Results and Discussion}

Performance on same trials. Summary statistics of the conditions of interest are shown in Table 8. The RT data for same trials were entered into a two-way repeated measures ANOVA. Here task (different side, different identity, both different) and display position (central, ipsilateral, contralateral) acted as fixed factors. Subjects was entered as a random factor. The analysis revealed statistically significant main effects of task $[F(2,22)=4.35$, $p<.05]$ and display position $[F(2,22)=16.75, p<.001]$. Subjects were generally faster in responding "same" in the both different task than in the other single-dimension tasks, and subjects were slower in responding "same" when the target letter appeared peripherally than when it appeared centrally. This overall pattern was somewhat complicated by a statistically significant task $\times$ display position interaction $[F(4,44)=3.31, p<.05]$. Subjects were particularly slow in responding "same" in the different position task when the target fell in the ipsilateral field. There is no obvious explanation for this finding.

The transformed error data were analyzed in a fashion similar to that used for the RT data. There were no statistically significant results in this analysis $[F(2,22)=$ $3.34, p=.054$ for the main effect of task; $F(2,22)=2.15$, $p>.05$ for the main effect of display position; $F(4,44)=$ $2.10, p>.05$ for the task $\times$ display position interaction].

Table 8

Summary Statistics of Reaction Times (Means, in Milliseconds, With Standard Deviations) and Mean Percentage Error (PE) Data for Same Trials in Experiment 4

\begin{tabular}{|c|c|c|c|c|c|c|c|c|c|}
\hline \multirow{3}{*}{$\begin{array}{l}\text { Experimental } \\
\text { Task }\end{array}$} & \multicolumn{9}{|c|}{ Display Position } \\
\hline & \multicolumn{3}{|c|}{ Central } & \multicolumn{3}{|c|}{ Ipsilateral } & \multicolumn{3}{|c|}{ Contralateral } \\
\hline & $M$ & $S D$ & $\mathrm{PE}$ & $M$ & $S D$ & PE & $M$ & $S D$ & $\mathrm{PE}$ \\
\hline ifferent side & & & 6 & & 129 & 11 & 574 & & r \\
\hline & 548 & 125 & 1 & 571 & & 8 & 583 & 126 & \\
\hline oth different & 497 & 97 & 6 & 539 & 98 & 7 & 535 & 111 & 6 \\
\hline
\end{tabular}

Performance was not compromised by any form of speederror tradeoff.

Performance on different trials. Summary statistics of the conditions of interest are shown in Table 9. The RT data for different trials were analyzed in the same manner as the RT data for same trials. The ANOVA revealed statistically significant main effects of task $[F(2,22)=$ $4.16, p<.05]$ and display position $[F(2,22)=4.55, p<$ $.05]$. The task $\times$ display position interaction failed to reach statistical significance $[F(4,44)=1.36, p>.05]$.

An HSD test of the statistically significant main effect of display position revealed that subjects were generally faster in responding "different" when the target display occurred centrally than when it occurred peripherally [although only the comparison between the central condition and the contralateral condition reached statistical significance $(p<.05)]$.

The statistically significant main effect of display position was of prime importance since it was predicted that the redundancy gain effect found previously in the data for the different trials in Experiment 3 should obtain here. Given this prediction, the main effect of task was decomposed using planned comparisons. This analysis revealed that, whereas there was no overall difference in the speed of responding "different" in the two single-dimension tasks $[F<1.0$ for the $1,-1,0$ contrast (the ordering of the tasks being different side, different identity, and both different)], subjects were faster in making different responses in the both different task than in the two single-dimension tasks $[F(1,11)=7.47, p<.05$ for the $-1,-1,+2$ contrast].

As before, the transformed error data were analyzed in a fashion similar to that used for the RT data, and as before, there were no statistically significant results in this analysis $[F(2,22)=3.14, p>.05$ for the main effect of display position; $F<1.0$ for the main effect of task and the task $X$ display position interaction]. Performance was not compromised by any form of speed-error tradeoff.

The central finding was a redundancy gain effect similar to that reported in Experiment 3. That is, subjects were quicker to respond "different" when there were mismatches on both the relative position and the identity dimensions than when there was a mismatch on only one of these dimensions. To further examine this pattern of performance, the data from the different trials were analyzed in accordance with the procedures described in Experiment 3. Again, only the data from the central different trials were considered and were broken down according to task. (For ease of comparison with the results of Experiment 3, the data from the different side task map onto the same identity/other side data, the data from the different identity task map onto the different identity/same side data, and the data from the both different task map onto the different identity/other side data.) Separate Vincentized CDFs for these three categories of trials are shown in Figure 4. This figure clearly illustrates the redundancy gain effect because the CDF for the both different task falls to the left of the CDFs for the single- 
Table 9

Summary Statistics of Reaction Times (Means, in Milliseconds, With Standard Deviations) and Mean Percentage Error (PE) Data for Different Trials in Experiment 4

\begin{tabular}{|c|c|c|c|c|c|c|c|c|c|}
\hline \multirow{3}{*}{$\begin{array}{l}\text { Experimental } \\
\text { Task } \\
\end{array}$} & \multicolumn{9}{|c|}{ Display Position } \\
\hline & \multicolumn{3}{|c|}{ Central } & \multicolumn{3}{|c|}{ Ipsilateral } & \multicolumn{3}{|c|}{ Contralateral } \\
\hline & $M$ & $S D$ & $\overrightarrow{\mathrm{PE}}$ & $M$ & $S D$ & $\overline{\mathrm{PE}}$ & $M$ & $S D$ & $\overline{P E}$ \\
\hline Different sid & 597 & 94 & 6 & 630 & 113 & 10 & 661 & 101 & 8 \\
\hline Differer & 595 & 130 & 6 & 622 & 128 & 9 & 618 & 118 & 6 \\
\hline Both different & 565 & 108 & 6 & 566 & 84 & 7 & 576 & 123 & 8 \\
\hline
\end{tabular}

dimension tasks. Indeed, the present data and those reported in Experiment 3 are similar in nearly all respects (see Figure 2). In order to analyze the current redundancy effect further, the summed CDF needed to be computed from the data for the two single-dimension tasks. In turn, this summed CDF needed to be compared with the CDF for the redundant signals trials (i.e., compared with the data from the both different task). Figure 5 shows the summed and redundant signals CDFs.

Prime interest now was whether the inequality expressed in Equation 2 was violated anywhere in the data shown in Figure 5. Any violation of the inequality would have occurred if the summed CDF was situated to the right of the redundant signals CDF. Visual inspection of Figure 5 shows that the inequality was apparently violated in two places-at the 5th and 15 th percentile points. However, to examine this possibility further, the data sets were taken for these two points and were analyzed using separate $t$ tests. In neither case were there statistical grounds for arguing that the inequality had been violated. There was no statistical difference found between the two CDFs at either the 5 th percentile point $[t(11)=0.54$, $p>.05$, two-tailed test] or the 15 th percentile point $[t(11)$ $=0.23, p>.05$, two-tailed test]. This result suggests that, in keeping with the results from Experiment 3 , the present data are consistent with a separate activation model and not a coactivation model of the processing of identity and relative position. More importantly, though, the present data cast considerable doubt on the congruence account of performance in the tasks.

\section{GENERAL DISCUSSION}

Initially, three experiments were reported that examined the manner in which item identity and relative position information are recovered from visual input. A successive same/different matching paradigm was developed in which a prime display preceded the presentation of a target display. Each display contained a reference object (a "+") and a located object (a letter). The letter fell to either the right or the left of the " + ." In Experiment 1, subjects were asked to carry out identity judgments on the letters and essentially to ignore positional information. In broad terms, the results showed that subjects were unaffected by a change in the relative position of the letter across the two displays when making the identity judg- ments. This was the first piece of evidence to suggest that the coding and recovery of item identity and relative position information are carried out by separate processing subsystems. In Experiment 2, subjects were asked to carry out relative position judgments and essentially to ignore letter identity information. The results were clear in showing that subjects were unable to ignore identity information in making the relative position judgments. Subjects were slower in making these judgments when the letters were different than when they were the same. Together with the results of Experiment 1, this was taken to further suggest that item identity was available prior to relative position information. However, this particular conclusion was placed in question by the results of Experiment 3 . In this experiment, subjects had to combine both item identity and relative position information: They had to respond "same" only if the same letter appeared on the same side of the cross in the two displays. The same trials data indicated that subjects were generally quicker in making these responses when the target display occurred centrally than when it occurred peripherally. In other words, there was a strong repetition priming effect (Miller, 1988). However, the more interesting effects related to performance on different trials. Here subjects were quicker in responding "different" if there was a change in both letter identity and relative position across the prime and target displays than when only identity or relative position changed.

Initially the analysis of this redundancy gain effect was taken as support for a model in which separate subsystems compute item identity and relative position concurrently, but quite independently. In view of the possibility

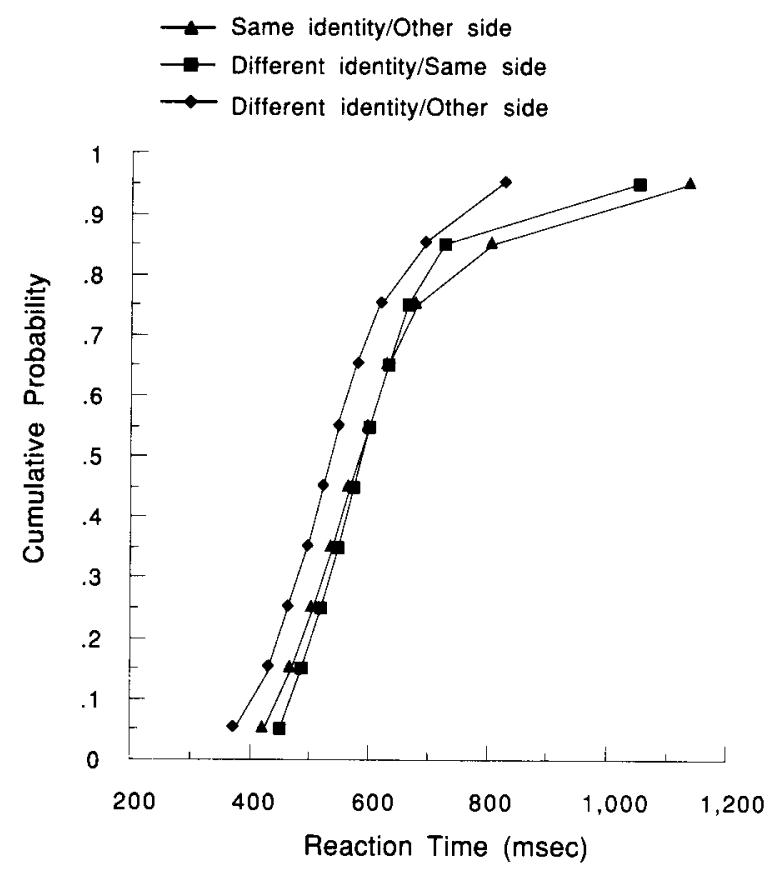

Figure 4. Graph showing the cumulative probability density functions for the different side trials, the different identity trials, and the both different trials. 


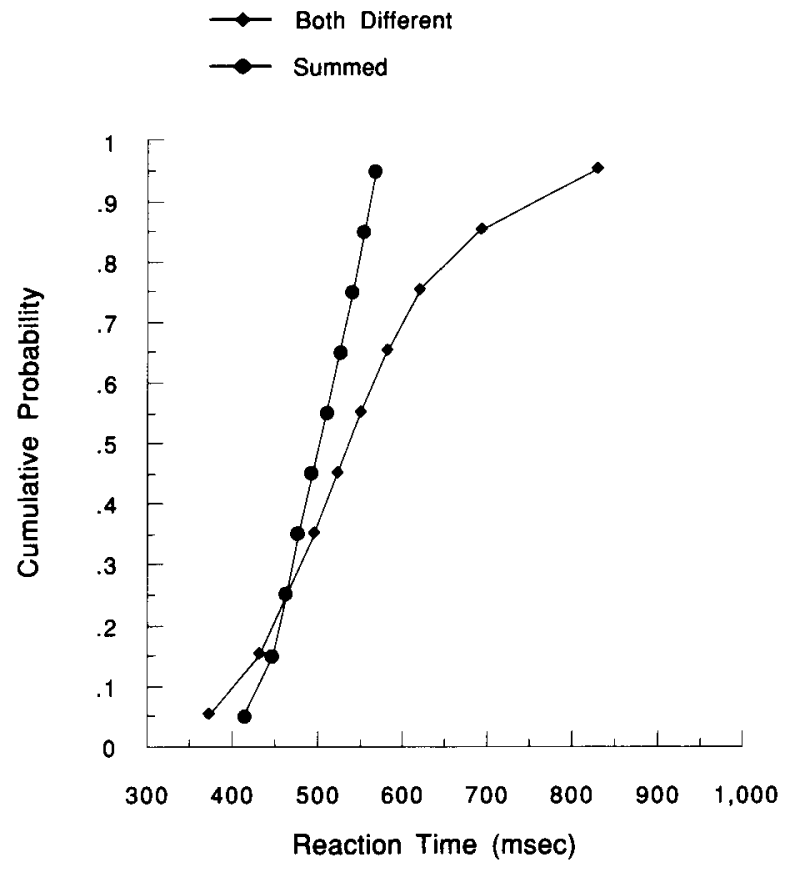

Figure 5. Graph showing the cumulative probability density function for the both different trials and the summed cumulative probability density function for the different side and the different identity trials.

of the congruence account, however, such a perceptual account of the results was questioned and a final experiment (Experiment 4) was carried out. In the final experiment, performance in three tasks was examined. In the two single-dimension tasks, subjects could selectively attend to one dimension and ignore the other. Information on the other dimension was irrelevant to the task. In the both different task, however, a correct response could be made on the basis of information on either dimension. On different trials, the identity of the letter changed, as did its relative position. Comparing across these tasks, it was discovered that the redundancy gain effect reported in Experiment 3 was also present in the data from Experiment 4 . Therefore, the effect was probably not due to response factors: In Experiment 4, the possible confounds on the different trials were removed. The data yet again suggested that relative position and identity were computed by independent subsystems.

Such a claim, however, must be assessed against the pattern of results that emerged in the first two experiments. A basic finding here was that whereas subjects appeared to be able to ignore location information in recovering item identity, they were unable to ignore identity information in recovering location information. Initially, this pattern of results was assumed to be most consistent with the idea that identity information is recovered and made explicit prior to relative position information. Such an account does not seem tenable given the data from Experiments 3 and 4. Both experiments revealed a redundancy gain effect; responses were generally quicker when mismatches resulted on both dimensions than when a mismatch occurred on just one. This result is most easily accommodated if it is accepted that, occasionally, relative position was recovered prior to identity. Indeed, analysis of performance on the two single-dimension tasks in Experiment 4 revealed that there was no difference in response speed across the different side and different identity tasks: Subjects were as quick to make identity judgments as they were to make relative position judgments. This seems to suggest that the recovery of relative position and identity generally occur within the same time span.

Caution is, nevertheless, warranted in attempting to claim that the processing of relative position and identity are completely insulated from each other. It remains possible that a more sophisticated method might reveal that important dependencies do exist between the recovery of relative position and identity. ${ }^{3}$ Indeed, the results of Experiment 2 do seem to suggest that information concerning item identity can interfere with the processes concerned with relative position under certain circumstances. Here subjects were slowed in responding "same" on relative position trials when the identity of the prime and target were different. Perhaps one way to think of this effect is that it shows that, in attempting to establish a correspondence across successive displays between the different letters (Ullman, 1979), the visual system generates an interrupt signal when the identity of a given object changes even though its position relative to some landmark remains the same. Such a change in identity may be taken by the visual system as an indication of the presentation of a new object at a location previously occupied by a different object. In turn, the acknowledgment of such an interrupt signal results in some form of rechecking, and hence subjects are slowed in making the relative position judgment. So, although the present data do suggest that the recovery of relative position and identity typically proceed independently, important dependencies are apparent when the visual system registers a change in the identity of a previously seen object.

One way forward might be to think in terms of there being two components that deal separately with identityspecific and identity-independent positional encoding, in the manner discussed by Miller (1988). However, a perhaps more parsimonious account can be advanced in terms of an interactive race model of processing (Mordkoff \& Yantis, 1991). Like the independent race and coactivation models of processing, the interactive race model posits separate mechanisms (channels) for the recovery of relative position and identity. Unlike both the independent race and coactivation models, the interactive race model allows for information to be exchanged across the two channels prior to the computation of a response decision. Such information exchange is known as "interchannel crosstalk" (Mordkoff \& Yantis, 1991, p. 522). The important proviso that must be considered given the present data is that information can only pass from the identity channel to the relative position channel. Detection of a change in identity slows responding to relative position. 
In closing, it is clear that the present data provide only some early indications about how relative position and identity may be recovered by the visual system. On the one hand, future empirical work might focus on the particular asymmetry in interference that the present work has uncovered. However, a perhaps more pressing and interesting endeavor would be to examine the degree to which attentional processes operate in relative and not absolute spatial coordinates.

\section{REFERENCES}

ANSTIS, S. M. (1974). A chart illustrating variations in acuity with retinal position. Vision Research, 14, 589-592.

AtKinson, J., \& BradDick, O. J. (1989). "Where" and "what" in visual search. Perception, 18, 181-189.

BundESEN, C. (1991). Visual selection of features and objects: Is location special? A reinterpretation of Nissen's (1985) findings. Perception \& Psychophysics, 50, 87-89.

Bundesen, C. (1993). The notion of elements in the visual field in a theory of visual attention: A reply to van der Velde and van der Heijden (1993). Perception \& Psychophysics, 53, 350-352.

Cave, K. R., \& Pashler, H. (1995). Visual selection mediated by location: Selecting successive visual objects. Perception \& Psychophysics, 57, 421-432.

Clark, H. H., \& Chase, W. G. (1972). On the process of comparing sentences against pictures. Cognitive Psychology, 3, 472-517.

EGETH, H. E., \& MORDKOFF, J. T. (1991). Redundancy gain revisited: Evidence for parallel processing of separable dimensions. In G. Lockhead \& J. Pomerantz (Eds.), The perception of structure: Essays in honor of Wendell R. Garner (pp. 131-143). Washington, DC: American Psychological Association.

ERIKSEN, C. W. (1988). A source of error in attempts to distinguish coactivation from separate activation in the perception of redundant targets. Perception \& Psychophysics, 44, 191-193.

Eriksen, C. W., Goettl, B., St. James, J. D., \& Fournier, L. R. (1989). Processing redundant signals: Coactivation, divided attention, or what? Perception \& Psychophysics, 45, 356-370.

FARELL, B. (1985). "Same"-"different" judgments: A review of current controversies in perceptual comparisons. Psychological Bulletin, 98 , 419-456.

Heathcote, A., \& Mewhort, D. J. K. (1993). Representation and selection of relative position. Journal of Experimental Psychology: Human Perception \& Performance, 19, 488-516.

Hinton, G. E. (1981). A parallel computation that assigns canonical object-based frames of reference. Proceedings of the Seventh International Joint Conference on Artificial Intelligence, 2, 683-685.

Hinton, G. E., \& Parsons, L. M. (1988). Scene-based and viewercentered representations for comparing shapes. Cognition, 30, 1-35.

HowARD, I. P. (1986). The perception of posture, self motion and the visual vertical. In K. R. Boff, L. Kaufman, \& J. P. Thomas (Eds.), Handbook of perception and human performance (Vol. 1, pp. 18.118.62). New York: Wiley.

Johnston, J. C., \& Pashler, H. (1990). Close binding of identity and location in visual feature perception. Journal of Experimental Psychology: Human Perception \& Performance, 16, 843-856.

LINDSAY, P. H., \& NORMAN, D. A. (1972). Human information processing: An introduction to psychology. New York: Academic Press.

LoGAN, G. D. (1995). Linguistic and conceptual control of visual spatial attention. Cognitive Psychology, 28, 103-174.

LoGAN, G. D., \& COMPTON, B. J. (1996). Distance and distraction effects in the apprehension of spatial relations. Journal of Experimental Psychology: Human Perception \& Performance, 22, 159-172.

Lu, C.-H., \& Proctor, R. W. (1995). The influence of irrelevant location information on performance: A review of the Simon and spatial Stroop effects. Psychonomic Bulletin \& Review, 2, 174-207.

MilleR, J. (1982). Divided attention: Evidence for coactivation with redundant signals. Cognitive Psychology, 14, 247-279.
MiLler, J. (1988). Components of the location probability effect in visual search tasks. Journal of Experimental Psychology: Human Perception \& Performance, 14, 453-471.

Monheit, M. A., \& Johnston, J. C. (1994). Spatial attention to arrays of multidimensional objects. Journal of Experimental Psychology: Human Perception \& Performance, 20, 691-708.

MordKoff, J. T., \& YANTIS, S. (1991). An interactive race model of divided attention. Journal of Experimental Psychology: Human Perception \& Performance, 17, 520-538.

MordKoff, J. T., Yantis, S., \& Egeth, H. E. (1990). Detecting conjunctions of color and form in parallel. Perception \& Psychophysics, 48, 157-168.

NisSEN, M. J. (1985). Accessing features and objects: Is location special? In M. I. Posner \& O. S. M. Marin (Eds.), Attention and performance $X I$ (pp. 205-219). Hillsdale, NJ: Erlbaum.

Quinlan, P. T. (1995). Evidence for the use of scene-based frames of reference in two-dimensional shape recognition. Spatial Vision, 9, 101-125.

RATCLIFF, R. (1979). Group reaction time distributions and an analysis of distribution statistics. Psychological Bulletin, 86, 446-461.

ROBERTSON, L. C. (1995). Covert orienting in scene-based reference frames: Orientation priming and visual field differences. Journal of Experimental Psychology: Human Perception \& Performance, 21, 707-718.

SAGI, D., \& JUlesz, B. (1985). "Where" and "what" in vision. Science, 228, 1217-1219.

Shaw, M. L., \& Shaw, P. (1977). Optimal allocation of cognitive resources to spatial location. Journal of Experimental Psychology: Human Perception \& Performance, 3, 201-211.

Treisman, A. (1988). Features and objects: The Fourteenth Bartlett Memorial Lecture. Quarterly Journal of Experimental Psychology, 40A, 201-234.

Treisman, A., \& Gelade, G. (1980). A feature-integration theory of attention. Cognitive Psychology, 12, 97-136.

Treisman, A., Vieira, A., \& Hayes, A. (1992). Automaticity and preattentive processing. American Journal of Psychology, 105, 341-362.

TSAL, N., \& LAVIE, Y. (1993). Location dominance in attending to color and shape. Journal of Experimental Psychology: Human Perception \& Performance, 19, 131-139.

Ullman, S. (1979). The interpretation of visual motion. Cambridge, MA: MIT Press.

Van der Velde, F., \& van der Heijden, A. H. C. (1993). An element in the visual field is just a conjunction of attributes: A critique of Bundesen (1991). Perception \& Psychophysics, 53, 345-349.

WINER, B. J. (1962). Statistical principles in experimental design. New York: McGraw-Hill.

WoLFE, J. M. (1994). Guided Search 2.0: A revised model of visual search. Psychonomic Bulletin \& Review, 1, 202-238.

\section{NOTES}

1. As a reviewer pointed out, discrimination of the $E$ and the $F$ depends upon detecting the presence of the small, lower horizontal bar in the E. On these grounds, detecting a feature is perfectly correlated with the identity judgment. An issue therefore remains over the degree to which the present experiments reveal identity versus featural processing. Such an issue can be resolved only by future experiments.

2. This particular account of performance was suggested by Roger Remington during the review process.

3. It would, perhaps, be premature to argue too strongly for strict independence given the failure to discover convincing evidence for the strict independence of processing of other object attributes. For example, although evidence for the strict independence of processing of color and shape was claimed by Nissen (1985) in an earlier study, on a more careful analysis, Monheit and Johnston (1994) have shown that this evidence is suspect.

(Manuscript received June 5, 1996; revision accepted for publication January 14, 1997.) 